\title{
PUBLICACIONES SOBRE LITERATURA FRANCESA EN ESPAÑA (2004)
}

AlicIA YlLERA

UNED. Madrid

ayllera@flog.uned.es

\section{RESUMEN}

Bibliografía sobre Literatura francesa publicada en España en 2004.

PALABRAS ClAVE: Filología francesa; Literatura; Bibliografía; España.

RÉSUMÉ

Bibliographie des études sur la Littérature française publiées en Espagne pendant l'année 2004.

MoTS-CLEF: Philologie française: Littérature; Bibliographie; Espagne.

ÍNDICE

1. Obras colectivas. Revistas

2. Edad Media

3. Siglo XVI

4. Siglo XVII

5. Siglo XVIII

6. Siglo XIX

7. Siglo $x x$

8. Varios siglos 
9. Literatura de expresión francesa. Literatura en lengua francesa fuera de Francia

10. Literatura de viajes

11. Literatura comparada. Recepción literaria. Literatura y cine

12. Historia de las ideas literarias. Crítica literaria. Géneros. Estudios de temas

13. Estudios sobre la traducción literaria

14. Bibliografías. Estados de la cuestión

\section{Obras COLECTIVAS. Revistas}

Estudios de Lengua y Literatura Francesas 15 (2004).

Francofonía (Universidad de Cádiz) 13 (2004).

Anales de Filología Francesa. La traducción (Universidad de Murcia) 12 (2004): 451 pp.

Confluencias poéticas. Estética, recepción y traducción de la poesía francesa contemporánea.

Marie-France Borot \& Alicia Piquer Desvaux (eds.). Barcelona: PPU, 2004, 177 pp.

El discurso sobre la traducción en la España del siglo XVIII. Estudio y antología. M.' Jesús García Garrosa \& Francisco Lafarga (eds.). Kassel: Edition Reichenberger, 2004, 466 pp. («Problemata literaria», 61).

Escriptores i cultures, Marta Segarra \& Àngels Carabí (eds.). Barcelona: Pòrtic, 2004, 255 pp.

Historia de la traducción en España. Francisco Lafarga \& Luis Pegenaute (eds.). Salamanca: Ambos Mundos, 2004 («Biblioteca de traducción», 9).

L'Autre et soi-même. La identidad y la alteridad en el ámbito francés y francófono. Editores: María Pilar Suárez, Margarita Alfaro, André Bénit, Patricia Martínez, Carmen Mata \& Didier Tejedor. Madrid: Universidad Autónoma de Madrid, 2004, 778 pp.

Logosphère. Revista de Estudios Lingüísticos y Literarios (Universidad de Granada, Grupo de Investigación HUM 733). Identités 0 (2004): XVI, 185 pp.

Palabras y recuerdos. Homenaje a Rosa Maria Calvet Lora. Edición de M. ${ }^{a}$ Rosario Ozaeta, Doina Popa-Liseanu \& Alicia Yllera. Madrid: UNED, Departamento de Filología Francesa, 2004, 233 pp.

Premsa hispànica i literatura francesa al segle XIX: petites $i$ grans ciutats/Prensa hispánica y literatura francesa en el siglo XIX: pequeñas y grandes ciudades. Marta Giné \& Yolanda Domínguez (eds.). Lleida: Edicions de la Universitat de Lleida, 2004, $361 \mathrm{pp.}$

Renaissance \& Classicisme. Homenatge a Caridad Martinez. Francisco Lafarga \& Marta Segarra (eds.). Barcelona: PPU, 2004, 368 pp.

\section{EDAD MEDIA}

Bermejo, Esperanza, «Hacia una definición de la función de la mujer en Partonopeus de Blois», Isla abierta: estudios franceses en memoria de Alejandro Cioranescu [X Coloquio de la Asociación de Profesores de Filología Francesa de la Universidad Española, La Laguna, 2001], José M. Oliver Frade (coord.). La Laguna: Universidad de La Laguna, Servicio de Publicaciones, 2004, t. I, pp. 195-212.

BERMEJO, Esperanza, «Las descripciones de monstruos en el Roman d'Alexandre de Thomas de Kent», Palabras y recuerdos. Homenaje a Rosa María Calvet Lora. Édition de M." Rosario Ozaeta, Doina Popa-Liseanu \& Alicia Yllera. Madrid: UNED, Departamento de Filología Francesa, 2004, pp. 31-37.

Salinero Cascante, M. a Jesús, «Lancelot, un Jonás artúrico», Revista de Literatura Medieval 14/ 2 (2002): 103-116. 
SALINERo CASCANTE, M. Jesús, «Gorre, un descenso al vientre de la muerte», Cuadernos de Investigación Filológica 27-28 (2001-2002): 121-138.

ClouET, Richard, «La symbolique de la révolte dans la littérature dite des rebelles au Moyen Âge: l'exemple de La chanson de Girart de Roussillon", Isla abierta: estudios franceses en memoria de Alejandro Cioranescu [X Coloquio de la Asociación de Profesores de Filología Francesa de la Universidad Española, La Laguna, 2001], José M. Oliver Frade (coord.). La Laguna: Universidad de La Laguna, Servicio de Publicaciones, 2004, t. I, pp. 349-362.

FRÉCHÉ, Bibiane, «Le Roman de la Rose de Gui di Mori», Isla abierta: estudios franceses en memoria de Alejandro Cioranescu [X Coloquio de la Asociación de Profesores de Filología Francesa de la Universidad Española, La Laguna, 2001], José M. Oliver Frade (coord.). La Laguna: Universidad de La Laguna, Servicio de Publicaciones, 2004, t. II, pp. 517-533.

García Pradas, Ramón, «Cuando identidad y alteridad se convierten en una identidad alterada: el caso de las Folies Tristan", L'Autre et soi-même. La identidad y la alteridad en el ámbito francés y francófono. Editores: María Pilar Suárez, Margarita Alfaro, André Bénit, Patricia Martínez, Carmen Mata \& Didier Tejedor. Madrid: Universidad Autónoma de Madrid, 2004, pp. 739-749.

García Pradas, Ramón, «En torno a la polémica cuestión de los orígenes en la leyenda tristaniana», Isla abierta: estudios franceses en memoria de Alejandro Cioranescu [X Coloquio de la Asociación de Profesores de Filología Francesa de la Universidad Española, La Laguna, 2001 ], José M. Oliver Frade (coord.). La Laguna: Universidad de La Laguna, Servicio de Publicaciones, 2004, t. II, pp. 535-554.

GonZÁlez DORESTE, Dulce, «Ociosa y Venus: del Roman de la Rose de Guillaume de Lorris (ms. 387 de la biblioteca de la Universidad de Valencia) a Le livre des échecs amoureux de Évrart de Conty», Isla abierta: estudios franceses en memoria de Alejandro Cioranescu [X Coloquio de la Asociación de Profesores de Filología Francesa de la Universidad Española, La Laguna, 2001 ], José M. Oliver Frade (coord.). La Laguna: Universidad de La Laguna, Servicio de Publicaciones, 2004, t. II, pp. 583-598.

JORDÁ Lliteras, Gabriel M.. y Vicens PUjol, Carlota, «El episodio de Baligant en el Cantar de Roldán: aportaciones lexicométricas», Isla abierta: estudios franceses en memoria de Alejandro Cioranescu [X Coloquio de la Asociación de Profesores de Filología Francesa de la Universidad Española, La Laguna, 2001], José M. Oliver Frade (coord.). La Laguna: Universidad de La Laguna, Servicio de Publicaciones, 2004, t. II, pp. 691-703.

LÓPEZ AlCARAZ, Josefa, «Equivalencias grafemo-fonemáticas en La Cantinela de Santa Eulalia». Revista Aemilianense. Revista internacional sobre la génesis y los orígenes históricos de las lenguas romances. Logroño: Fundación San Millán de La Cogolla, 2004, pp. $345-$ 356.

Mendoza Ramos, M. ${ }^{a}$ del Pilar, «Meleagant como modelo de malvado en Le Chevalier de la Charrete de Chrétien de Troyes", Isla abierta: estudios franceses en memoria de Alejandro Cioranescu [X Coloquio de la Asociación de Profesores de Filología Francesa de la Universidad Española, La Laguna, 2001], José M. Oliver Frade (coord.). La Laguna: Universidad de La Laguna, Servicio de Publicaciones, 2004, t. II, pp. 845-860.

Miñano Martínez, Evelio, "Les autres dans l'univers épique dans La Chanson des Saisnes», L'Autre et soi-même. La identidad y la alteridad en el ámbito francés y francófono. Editores: María Pilar Suárez, Margarita Alfaro, André Bénit, Patricia Martínez, Carmen Mata \& Didier Tejedor. Madrid: Universidad Autónoma de Madrid, 2004, pp. 321-332.

RIQUER Isabel de, «La narrativa después de Chrétien de Troyes: de la novela en verso a la novela en prosa», www.liceus.com, 2005, $26 \mathrm{pp}$. 
SUÁREZ, M. ${ }^{a}$ Pilar, “Visages de l'altérité dans le drame médiéval», L'Autre et soi-même. La identidad y la alteridad en el ámbito francés y francófono. Editores: María Pilar Suárez, Margarita Alfaro, André Bénit, Patricia Martínez, Carmen Mata \& Didier Tejedor. Madrid: Universidad Autónoma de Madrid, 2004, pp. 345-354.

VAlEntINI, Carlos, "Maistre Pierre Pathelin: avaricia, astucia y locura», Isla abierta: estudios franceses en memoria de Alejandro Cioranescu [X Coloquio de la Asociación de Profesores de Filología Francesa de la Universidad Española, La Laguna, 2001], José M. Oliver Frade (coord.). La Laguna: Universidad de La Laguna, Servicio de Publicaciones, 2004, t. III, pp. 1399-1407.

YLLERA, Alicia, «Los supuestos terrores del año 1000 (Una visión tergiversada del mundo medieval)», Palabras y recuerdos. Homenaje a Rosa María Calvet Lora. Édition de M. ${ }^{a}$ Rosario Ozaeta, Doina Popa-Liseanu \& Alicia Yllera. Madrid: UNED, Departamento de Filología Francesa, 2004, pp. 227-233.

Yllera, Alicia, Tristán e Iseo. Presentación y versión. Barcelona: Random House Mondadori, 2004, 302 pp.

YllerA, Alicia, Tristán e Iseo. Reconstrucción en lengua castellana e introducción, 16. ed. Madrid: Alianza Editorial, «Biblioteca Artúrica», 2004, 196 pp.

\section{SIGLO XVI}

Badía Cubas, Cristina, «La expresión del amor en la poesía de Louise Labé», Isla abierta: estudios franceses en memoria de Alejandro Cioranescu [X Coloquio de la Asociación de Profesores de Filología Francesa de la Universidad Española, La Laguna, 2001], José M. Oliver Frade (coord.). La Laguna: Universidad de La Laguna, Servicio de Publicaciones, 2004, t. I, pp. 135-146.

BELLENGER, Yvonne, «Ronsard et les poètes grecs et latins cités dans ses œuvres», Renaissance \& Classicisme. Homenatge a Caridad Martínez. Edición de Francisco Lafarga \& Marta Segarra. Barcelona: PPU, pp. 29-40.

BENITO DE LA FuENTE, Javier, «De la dedicación de las letras como sublimación en la cultura femenina del siglo XVI", Isla abierta: estudios franceses en memoria de Alejandro Cioranescu [X Coloquio de la Asociación de Profesores de Filología Francesa de la Universidad Española, La Laguna, 2001], José M. Oliver Frade (coord.). La Laguna: Universidad de La Laguna, Servicio de Publicaciones, 2004, t. I, pp. 165-177.

CASAlS, Jaume, «Sur la double racine du principe de la servitude volontaire», Renaissance \& Classicisme. Homenatge a Caridad Martínez. Edición de Francisco Lafarga \& Marta Segarra. Barcelona: PPU, pp. 87-91.

COCA MÉndez, Beatriz, Ética y estética de la desmesura en Gargantúa y Pantagruel de Rabelais. Edición electrónica en la base de datos Proquest Digital Dissertations. Proquest Information and Learning, 2004. (Tesis doctoral).

Cors, Montserrat, «Figuras de la evidencia en La Franciade», Renaissance \& Classicisme. Homenatge a Caridad Martínez. Edición de Francisco Lafarga \& Marta Segarra. Barcelona: PPU, pp. 41-52.

DEMERSON, Guy, «Le Discours de la servitude volontaire: une rhétorique datée», Renaissance \& Classicisme. Homenatge a Caridad Martínez. Edición de Francisco Lafarga \& Marta Segarra. Barcelona: PPU, pp. 93-109.

Gaston Elduayen, Luis, Rabelais. Madrid: Síntesis, 2004, 270 pp.

Gómez BedATE, Pilar, «Un Tombeau moderno para Ronsard», Renaissance \& Classicisme. Homenatge a Caridad Martinez. Edición de Francisco Lafarga \& Marta Segarra. Barcelona: PPU, pp. 277-281. 
LAZARD-MoISAN, Madeleine, «L'épître dédicatoire de Louise Labé et les préfaces féminines au XVI ${ }^{e}$ siecle», Renaissance \& Classicisme. Homenatge a Caridad Martínez. Edición de Francisco Lafarga \& Marta Segarra. Barcelona: PPU, pp. 65-71.

INCARDONA, Janine, «Jeux onomastiques dans les Comptes amoureux de Madame Jeanne Flore», Renaissance \& Classicisme. Homenatge a Caridad Martínez. Edición de Francisco Lafarga \& Marta Segarra. Barcelona: PPU, pp. 169-187.

MARTINez CUADRADO, Jerónimo, «Presencia de los clásicos latinos en Les Antiquitez de Rome», Isla abierta: estudios franceses en memoria de Alejandro Cioranescu [X Coloquio de la Asociación de Profesores de Filología Francesa de la Universidad Española, La Laguna, 2001], José M. Oliver Frade (coord.). La Laguna: Universidad de La Laguna, Servicio de Publicaciones, 2004 , t. II, pp. 825-843.

Popa-Liseanu, Doina, «Le féminisme éclairé des dames de la Renaissance», Renaissance \& Classicisme. Homenatge a Caridad Martínez. Edición de Francisco Lafarga \& Marta Segarra. Barcelona: PPU, pp. 73-84.

PUIGDOMĖNECH, Helena, «Machiavelli y Montaigne», Renaissance \& Classicisme. Homenatge a Caridad Martínez. Edición de Francisco Lafarga \& Marta Segarra. Barcelona: PPU, pp. 121139.

RIQUER Isabel de, «Las narradoras del "corazón comido": Jeanne Flore», Renasissance \& Classicisme. Homenatge a Caridad Martínez, Francisco Lafarga \& M. Segarra (eds.). Barcelona: PPU, 2004, pp. 143-167.

VERJAT, Alain, «L'aimable Cassandre», Renaissance \& Classicisme. Homenatge a Caridad Martinez. Edición de Francisco Lafarga \& Marta Segarra. Barcelona: PPU, pp. 53-63.

Weber, Henri, «Montaigne et Pomponazzi: convergences et divergences», Renaissance \& Classicisme. Homenatge a Caridad Martínez. Edición de Francisco Lafarga \& Marta Segarra. Barcelona: PPU, pp. 111-120.

\section{SIGLO XVII}

Dalla Valle, Daniela, "Presenza dei miti in una "nouvelle tragique": 1'Hyppolite Sarmate di JeanPierre Camus», Renaissance \& Classicisme. Homenatge a Caridad Martínez. Edición de Francisco Lafarga \& Marta Segarra. Barcelona: PPU, pp. 217-226.

Garcla Peinado, Miguel Ángel, «El "abbé" Cotin y el subgénero poético de los "énigmes" en la Francia del Xvil», Anales de Filología Francesa. La traducción 12 (2004): 119-133.

MARTínEZ, Caridad, Introducción y traducción de El médico volante, El amor médico, El médico a su pesar, El señor de Puercoñac, El enfermo imaginario de Molière. Madrid: Gredos, 2004 («Biblioteca Universal»).

Merino Garcia, M.` Manuela, «El título literario en la obra narrativa de Paul Scarton», La literatura en la literatura. Actas del XIV simposio de la Sociedad Española de Literatura General y Comparada. Edición de Magdalena León Gómez. Alcalá de Henares: Centro de Estudios Cervantinos, 2004, pp. 243-251.

OLIVER, María, «Molière y la elaboración teatral de una sabiduría cómica», Renaissance \& Classicisme. Homenatge a Caridad Martínez. Edición de Francisco Lafarga \& Marta Segarra. Barcelona: PPU, pp. 243-250.

Piquer DesvauX, Alicia, «En tomo al Bartoco: la poesía de Saint-Amant», Renaissance et Classicisme. Homenatge a Caridad Martínez. Francisco Lafarga \& Marta Segarra (eds.). Barcelona: PPU, 2004, pp. 201-216.

SegarRa, Marta, «La Princesse de Clèves y La carta (robada)», Renaissance \& Classicisme. Homenatge a Caridad Martínez. Edición de Francisco Lafarga \& Marta Segarra. Barcelona: PPU, pp. 301-313. 
SERRANo MAÑES, Montserrat, «Un divertissement de salon: le café, joli petit vice des précieuses», Isla abierta: estudios franceses en memoria de Alejandro Cioranescu [X Coloquio de la Asociación de Profesores de Filología Francesa de la Universidad Española, La Laguna, 2001], José M. Oliver Frade (coord.). La Laguna: Universidad de La Laguna, Servicio de Publicaciones, 2004, t. III, pp. 1293-1305.

Serrano Mañes, Montserrat, Donna Hortence: Nouvelle Espagnole. Edición crítica, introducción y notas de Montserrat Serrano Mañes. Universidad de Granada: Editorial Comares, 2004, $199 \mathrm{pp}$. [Nouvelle anónima del siglo XVII].

Yllera, Alicia, «Una novelita de Scarton y su fuente española: Le Châtiment de l'avarice», Renaissance \& Classicisme. Homenatge a Caridad Martínez. Edición de Francisco Lafarga \& Marta Segarra. Barcelona: PPU, 2004, pp. 227-241.

\section{SigLo XVIII}

BotXareu Vllaplana, Mercè, «Los personajes femeninos en los Cuentos de Voltaire», Renaissance \& Classicisme. Homenatge a Caridad Martínez. Edición de Francisco Lafarga \& Marta Segarra. Barcelona: PPU, pp. 251-260.

JiMÉNEZ, Dolores, «La aventura mediterránea de Prévost: La Juventud del Comendador de *** », Palabras y recuerdos. Homenaje a Rosa María Calvet Lora. Édition de M.a Rosario Ozaeta, Doina Popa-Liseanu \& Alicia Yllera. Madrid: UNED, Departamento de Filología Francesa, 2004, pp. 107-111.

LlORCA TONDA, M. ${ }^{a}$ Ángeles, «Diderot: critique littéraire», Isla abierta: estudios franceses en memoria de Alejandro Cioranescu [X Coloquio de la Asociación de Profesores de Filología Francesa de la Universidad Española, La Laguna, 2001], José M. Oliver Frade (coord.). La Laguna: Universidad de La Laguna, Servicio de Publicaciones, 2004, t. II, pp. 803-811.

MARRero MARrero, M. ${ }^{a}$ del Carmen, «La noción de libertad en la escritura femenina francesa del siglo XVIII", Isla abierta: estudios franceses en memoria de Alejandro Cioranescu [X Coloquio de la Asociación de Profesores de Filología Francesa de la Universidad Española, La Laguna, 2001], José M. Oliver Frade (coord.). La Laguna: Universidad de La Laguna, Servicio de Publicaciones, 2004, t. II, pp. 813-823.

ROMERo Alfaro, Elena, «El cuento de La belle et la bête de Madame Leprince de Beaumont», Isla abierta: estudios franceses en memoria de Alejandro Cioranescu [X Coloquio de la Asociación de Profesores de Filología Francesa de la Universidad Española, La Laguna, 2001], José M. Oliver Frade (coord.). La Laguna: Universidad de La Laguna, Servicio de Publicaciones, 2004, t. III, pp. 1187-1201.

VÁzQuez JiMÉnEz, Lydia, «El culto a Príapo en el siglo XVill», Isla abierta: estudios franceses en memoria de Alejandro Cioranescu [X Coloquio de la Asociación de Profesores de Filología Francesa de la Universidad Española, La Laguna, 2001], José M. Oliver Frade (coord.). La Laguna: Universidad de La Laguna, Servicio de Publicaciones, 2004, t. III, pp. 1409-1417.

\section{SIGLO XIX}

Alonso Garcí, Ana, "Ciudades como islas. La insularidad como estructura topográfica en las ciudades imaginarias de Jules Verne», Isla abierta: estudios franceses en memoria de Alejandro Cioranescu [X Coloquio de la Asociación de Profesores de Filología Francesa de la Universidad Española, La Laguna, 2001], José M. Oliver Frade (coord.). La Laguna: Universidad de La Laguna, Servicio de Publicaciones, 2004, t. I, pp. 45-62. 
Álvarez DE LA RoSA, Antonio: «Literatura y erotismo en el gran viaje de Flaubert», La estirpe de Telémaco (Estudios sobre la literatura y el viaje), Petra-Iraides Cruz y José Ismael Gutiérrez (eds.), Madrid, Editorial Betania, 2004, págs. 19-27

ANOLL, Lídia, «Contes d'une grand-mère: un autre visage de George Sand?», George Sand, 18042004. L'ile et la dame de Nohant. Carlota Vicens Pujol (ed.). Palma: Estudi Genera Lul lià, 2004, pp. 191-208. («Mallorca en el món»).

ARAGÓN RoNSANO, Flavia, «Los hermanos Goncourt y la sacralización de la literatura», Isla abierta: estudios franceses en memoria de Alejandro Cioranescu [X Coloquio de la Asociación de Profesores de Filología Francesa de la Universidad Española, La Laguna, 2001], José M. Oliver Frade (coord.). La Laguna: Universidad de La Laguna, Servicio de Publicaciones, 2004, t. I, pp. 103-117.

BÉNIT, André, «La Belgique hugolienne: copie au antithèse de la France?», L'Autre et soi-même. La identidad y la alteridad en el ámbito francés y francófono. Editores: María Pilar Suárez, Margarita Alfaro, André Bénit, Patricia Martínez, Carmen Mata \& Didier Tejedor. Madrid: Universidad Autónoma de Madrid, 2004, pp. 63-73.

BolXAReu, Mercè, «La juive de Scribe y su relación con la leyenda de la Judía de Toledo», Palabras y recuerdos. Homenaje a Rosa María Calvet Lora. Édition de M. ${ }^{a}$ Rosario Ozaeta, Doina PopaLiseanu \& Alicia Yllera. Madrid: UNED, Departamento de Filología Francesa, 2004, pp. 39-43.

CORREDOR PlajA, Anna-María, «El paisaje en Lettres de mon moulin de Alphonse Daudet», Isla abierta: estudios franceses en memoria de Alejandro Cioranescu [X Coloquio de la Asociación de Profesores de Filología Francesa de la Universidad Española, La Laguna, 2001], José M. Oliver Frade (coord.). La Laguna: Universidad de La Laguna, Servicio de Publicaciones, 2004, t. I, pp. 363-373.

Curell, Clara, Gonzálfz de URiarte, Cristina y Oliver Frade, José M., «El paisaje canario en los relatos de viajes franceses de la época romántica». Corpo e Paisagem Românticos. Lisboa: Edições Colibri, 2004, pp. 21 1-222.

GINE JANER, Marta, «La alteridad y la identidad mediante la metáfora animal: Le Chevalier des Touches y $L$ 'enfant », $L$ 'Autre et soi-même. La identidad y la alteridad en el ámbito francés y francófono. Editores: María Pilar Suárez, Margarita Alfaro, André Bénit, Patricia Martínez, Carmen Mata \& Didier Tejedor. Madrid: Universidad Autónoma de Madrid, 2004, pp. 751 763.

GiNÉ, Marta, «Le château imaginaire de Villiers de l'Isle-Adam», $\hat{O}$ saisons, ô châteaux. Châteaux et littérature des Lumières à l' aube de la Modernité (1764-1914). Clermont-Ferrand: Presses de l'Université Blaise Pascal, 2004, pp. 333-346.

MARIÑo, Alicia, «El regreso de Véra», Palabras y recuerdos. Homenaje a Rosa María Calvet Lora. Édition de M.a Rosario Ozaeta, Doina Popa-Liseanu \& Alicia Yllera. Madrid: UNED, Departamento de Filología Francesa, 2004, pp. 133-138.

Miravet Fuster, Ana, «Mirada y tiempo: anatomía de un sentimiento en tres lieder de Émile Augier y Charles Gounod», Palabras y recuerdos. Homenaje a Rosa María Calvet Lora. Édition de M. ${ }^{a}$ Rosario Ozaeta, Doina Popa-Liseanu \& Alicia Yllera. Madrid: UNED, Departamento de Filología Francesa, 2004, pp. 145-150.

Palacios Bernal, Concepción, «El amor en Nodier», Isla abierta: estudios franceses en memoria de Alejandro Cioranescu [X Coloquio de la Asociación de Profesores de Filología Francesa de la Universidad Española, La Laguna, 2001], José M. Oliver Frade (coord.). La Laguna: Universidad de La Laguna, Servicio de Publicaciones, 2004, t. II, pp. 961-976.

PRADO BIEZMA, Javier del, «Identidad y alteridad del Yo. La frontera interior", L'Autre et soi-même. La identidad y la alteridad en el ámbito francés y francófono. Editores: María Pilar Suárez, Margarita Alfaro, André Bénit, Patricia Martínez, Carmen Mata \& Didier Tejedor. Madrid: Universidad Autónoma de Madrid, 2004, pp. 573-598. 
SANTA, M. Àngels, «George Sand et la Chartreuse et Valldemossa», Littérature et architecture. Textes rassemblés par Laurence Richer. Lyon: C.E.D.I.C., Centre Jean Prévost, Université Jean Moulin, Lyon III, 2004, pp. 37-47.

SANTA, M." Àngels, «La estancia en Mallorca de George Sand y Spiridion», George Sand, 1804 2004. L'île et la dame de Nohant. Carlota Vicens Pujol (ed.). Palma: Estudi Genera Lul 'lià, 2004, pp. 61-71. («Mallorca en el món»).

Velázquez EzQuerra, J. Ignacio, "Les demi-vierges, de Prévost: tres apuntes de análisis», Palabras y recuerdos. Homenaje a Rosa María Calvet Lora. Édition de M. ${ }^{a}$ Rosario Ozaeta, Doina Popa-Liseanu \& Alicia Yllera. Madrid: UNED, Departamento de Filología Francesa, 2004, pp. 219-225.

VERJAT, Alain, Introducción, traducción y notas a Noventa y tres de Victor Hugo. Madrid: Gredos, 2004,479 pp.

\section{SigLo $\mathrm{XX}$}

Alfaro, Margarita, «Cosmopolitismo e imágenes del otro en Blaise Cendrars», L'Autre et soimême. La identidad y la alteridad en el ámbito francés y francófono. Editores: María Pilar Suárez, Margarita Alfaro, André Bénit, Patricia Martínez, Carmen Mata \& Didier Tejedor. Madrid: Universidad Autónoma de Madrid, 2004, pp. 51-61.

ARRÁEZ Llobregat, José Luis, «Dominique Rolin: un je en quête d'un/ du passé; un moi à la rencontre d'un/ de l'avenir», Isla abierta: estudios franceses en memoria de Alejandro Cioranescu [X Coloquio de la Asociación de Profesores de Filología Francesa de la Universidad Española, La Laguna, 2001], José M. Oliver Frade (coord.). La Laguna: Universidad de La Laguna, Servicio de Publicaciones, 2004, t. 1, pp. 71-83.

ARREGU BARRAGÁN, Natalia, «El texto literario como apunte biográfico de su autor: Romain Kacew en La vie devant soi», Logosphère. Revista de Estudios Lingüisticos y Literarios. Identités 0 (2004): 21-33.

ARTUÑEDO Guillén, Belén, «El nombre de lugar como recurso de poetización de la ciudad en Les nouveaux mystères de Paris de Léo Malet», Isla abierta: estudios franceses en memoria de Alejandro Cioranescu [X Coloquio de la Asociación de Profesores de Filología Francesa de la Universidad Española, La Laguna, 2001], José M. Oliver Frade (coord.). La Laguna: Universidad de La Laguna, Servicio de Publicaciones, 2004, t. I, pp. 119-134.

Avendaño ANGUITA, Lina, «Portrait d' un inconnu: zones ténébreuses et grises d'un jeu malsain», Logosphère. Revista de Estudios Lingüísticos y Literarios. Identités 0 (2004): 35-44.

BENOIT, Claude, "Amores sáficos y escritura autobjografica en los albores del siglo XX ( $\mathrm{L}$. de Pougy, R. Vivien y N. Clifford Barney)", Isla abierta: estudios franceses en memoria de Alejandro Cioranescu [X Coloquio de la Asociación de Profesores de Filología Francesa de la Universidad Española, La Laguna, 20011, José M. Oliver Frade (coord.). La Laguna: Universidad de La Laguna, Servicio de Publicaciones, 2004, t. I, pp. 179-193.

Bernabe Gil, M. ${ }^{a}$ Luisa, «Le voyage du Chercheur d'or de Le Clézio: procédés narratifs», Logosphère. Revista de Estudios Lingüísticos y Literarios. Identités 0 (2004): 45-55.

BuRdeus, M. Dolores, "Insularidad y temas en oposición en La maison des Atlantes", Isla abierta: estudios franceses en memoria de Alejandro Cioranescu [ $\mathrm{X}$ Coloquio de la Asociación de Profesores de Filología Francesa de la Universidad Española, La Laguna, 2001], José M. Oliver Frade (coord.). La Laguna: Universidad de La Laguna, Servicio de Publicaciones, 2004, t. I, pp. 279-289 [de Angelo Rinaldi].

Camarero Arribas, Jesús, «L'être lettre (identité et textualité chez Jean Paul Sartre)», L'Autre et soi-même. La identidad y la alteridad en el ámbito francés y francófono. Editores: María Pilar 
Suárez, Margarita Alfaro, André Bénit, Patricia Martínez, Carmen Mata \& Didier Tejedor. Madrid: Universidad Autónoma de Madrid, 2004, pp. 599-610.

CAmarero, Jesús, «Hyperconstruction et mobilité», Le goût de la forme en littérature. Écritures et lectures à contraintes. Colloque de Cerisy. Jan Baetens y Bernardo Schiavetta (eds.). París: Noésis, 2004, pp. 182-201. [Michel Butor].

Cantón Rodriguez, M. ${ }^{a}$ Loreto, «La isla como espacio narrativo en la obra de J.M.G. Le Clézio», Isla abierta: estudios franceses en memoria de Alejandro Cioranescu [X Coloquio de la Asociación de Profesores de Filología Francesa de la Universidad Española. La Laguna, 2001], José M. Oliver Frade (coord.). La Laguna: Universidad de La Laguna. Servicio de Publicaciones, 2004, t. I, pp. 321-335.

CASAdo, Loreto, «A partir del signo ascendente de André Breton», Isla abierta: estudios franceses en memoria de Alejandro Cioranescu [X Coloquio de la Asociación de Profesores de Filología Francesa de la Universidad Española, La Laguna, 2001], José M. Oliver Frade (coord.). La Laguna: Universidad de La Laguna, Servicio de Publicaciones, 2004, t. I, pp. 337-347.

Cixous, Hélène, DeRrIDA, Jacques y SEgARRA, Marta (eds.), Lengua por venir/Langue à venir: seminario de Barcelona. Barcelona: Icaria, 2004, 158 pp.

Cortio Talavera, Adela, «Fortius altius citius. La visión autobiográfica e insular de dos patafísicos: Georges Perec y Boris Vian», Isla abierta: estudios franceses en memoria de Alejandro Cioranescu [X Coloquio de la Asociación de Profesores de Filología Francesa de la Universidad Española, La Laguna, 2001], José M. Oliver Frade (coord.). La Laguna: Universidad de La Laguna, Servicio de Publicaciones, 2004, t. I, pp. 375-389.

Díaz-CorRalejo Conde, Joaquín, «Bousquet, Carrière et Quignard, un discours autre», L'Autre et soi-même. La identidad y la alteridad en el ámbito francés y francófono. Editores: María Pilar Suárez, Margarita Alfaro, André Bénit, Patricia Martínez, Carmen Mata \& Didier Tejedor. Madrid: Universidad Autónoma de Madrid, 2004, pp. 713-716.

DURÁN, M." Jesús, «Descubrirse en el otro: la escritura autobiográfica de Georges Perec», L'Autre et soi-même. La identidad y la alteridad en el ámbito francés y francófono. Editores: María Pilar Suárez, Margarita Alfaro, André Bénit, Patricia Martínez, Carmen Mata \& Didier Tejedor. Madrid: Universidad Autónoma de Madrid, 2004, pp. 611-620.

Durand Guizion, Marie-Claire, «Sous le pont Max Jacob coule le jet», Isla abierta: estudios franceses en memoria de Alejandro Cioranescu [X Coloquio de la Asociación de Profesores de Filología Francesa de la Universidad Española, La Laguna, 2001 ], José M. Oliver Frade (coord.). La Laguna: Universidad de La Laguna, Servicio de Publicaciones, 2004, t. I, pp. 475-487.

FENOY, Blanca Liliana y ORTIZ SUÁREZ, Adriana, «Marguerite Duras: être hors là», Isla abierta: estudios franceses en memoria de Alejandro Cioranescu [X Coloquio de la Asociación de Profesores de Filología Francesa de la Universidad Española, La Laguna, 2001], José M. Oliver Frade (coord.). La Laguna: Universidad de La Laguna, Servicio de Publicaciones, 2004, t. II, pp. 509-516.

Figuerola CaBrol, M. ${ }^{a}$ Carme, «Biographie, histoire et fantastique dans le récit d'aventures: Nostradamus de Michel Zévaco", Poétiques du roman d'aventures. Alain-Michel Boyer et Daniel Couégnas (eds.). Nantes: Université de Nantes, 2004, pp. 69-82.

FISCHER HUBERT, Denise, «ldentité et altérité dans un roman de Didier Van Cauwelaert: Un aller simple», L'Autre et soi-même. La identidad y la alteridad en el ámbito francés y francófono. Editores: María Pilar Suárez, Margarita Alfaro, André Bénit, Patricia Martínez, Carmen Mata \& Didier Tejedor. Madrid: Universidad Autónoma de Madrid, 2004, pp. 369-389.

Garcla Martínez, Manuel, «L'altérité dans Le retour au désert de Bernard-Marie Koltès», L'Autre et soi-même. La identidad y la alteridad en el ámbito francés y francófono. Editores: María 
Pilar Suárez, Margarita Alfaro, André Bénit, Patricia Martínez, Carmen Mata \& Didier Tejedor. Madrid: Universidad Autónoma de Madrid, 2004, pp. 727-737.

GuIJARRo Garcia, Rafael, «L'identité du sujet énonciateur à l'origine des perceptions visuelles représentées dans Moderato Cantabile», Logosphère. Revista de Estudios Lingüísticos y Literarios. Identités 0 (2004): 99-114.

Hermosilla Álvarez, Concepción, "Sophie Calle ou soi-même comme autre", L'Autre et soimême. La identidad y la alteridad en el ámbito francés y francófono. Editores: María Pilar Suárez, Margarita Alfaro, André Bénit, Patricia Martínez, Carmen Mata \& Didier Tejedor. Madrid: Universidad Autónoma de Madrid, 2004, pp. 309-319.

Herrero Cecilia, Juan, «Fantasía, desdoblamiento y subversión de los géneros en Le syndrome du scaphandrier, una novela de Serge Brussolo", Palahras y recuerdos. Homenaje a Rosa María Calvet Lora. Édition de M. ${ }^{a}$ Rosario Ozaeta, Doina Popa-Liseanu \& Alicia Yllera. Madrid: UNED, Departamento de Filología Francesa, 2004, pp. 101-106.

LASO Y LEON, Esther, «Portraits de migrants dans la littérature de jeunesse française», L'Autre et soi-même. La identidad y la alteridad en el ámbito francés y francófono. Editores: María Pilar Suárez, Margarita Alfaro, André Bénit, Patricia Martínez, Carmen Mata \& Didier Tejedor. Madrid: Universidad Autónoma de Madrid, 2004, pp. 285-293.

MARTINEZ GarCiA, Patricia, "Sujet autobiographique, sujet de fiction et quête identitaire", $L$ 'Autre et soi-même. La identidad y la alteridad en el ámbito francés y francófono. Editores: María Pilar Suárez, Margarita Alfaro, André Bénit, Patricia Martínez, Carmen Mata \& Didier Tejedor. Madrid: Universidad Autónoma de Madrid, 2004, pp. 621-631.

MOREELS, Isabelle, «À la recherche de l'autre sur les pistes du "Nouveau Roman" explorées par Jacques-Gérard Linze», L'Autre et soi-même. La identidad y la alteridad en el ámbito francés y francófono. Editores: María Pilar Suárez, Margarita Alfaro, André Bénit, Patricia Martínez, Carmen Mata \& Didier Tejedor. Madrid: Universidad Autónoma de Madrid, 2004, pp. 633-643.

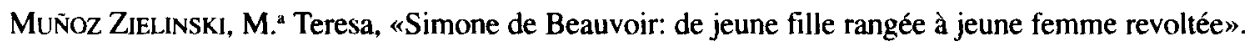
Revista Electrónica Tonos Digital (Universidad de Murcia) 8.

Oliver Frande, José M. y CUrell, Clara, «El verdino de Valentine Penrose», Nerter. Una revista dedicada a la Literatura, el Arte y el Conocimiento 7 (2004): 71-78.

PAREja Ríos, Patricia, «Écriture et liberté à la lumière surréaliste», Isla abierta: estudios franceses en memoria de Alejandro Cioranescu [X Coloquio de la Asociación de Profesores de Filología Francesa de la Universidad Española, La Laguna, 2001 ], José M. Oliver Frade (coord.). La Laguna: Universidad de La Laguna, Servicio de Publicaciones, 2004, t. II, pp. 993-1007.

Peñalva García, M. ${ }^{a}$ Eugenia, «La educación o la búsqueda de la identidad en Les Thibault de Roger Martin du Gard», L'Autre et soi-même. La identidad y la alteridad en el ámbito francés y francófono. Editores: María Pilar Suárez, Margarita Alfaro, André Bénit, Patricia Martínez, Carmen Mata \& Didier Tejedor. Madrid: Universidad Autónoma de Madrid, 2004, pp. 765-774.

PERAl CRESPO, Amelia, «Du je(u) à l'ecriture dans Souffle et La d'Hélène Cixous», Isla abierta: estudios franceses en memoria de Alejandro Cioranescu [X Coloquio de la Asociación de Profesores de Filología Francesa de la Universidad Española, La Laguna, 2001], José M. Oliver Frade (coord.). La Laguna: Universidad de La Laguna, Servicio de Publicaciones, 2004, t. II, pp. 1009-1021.

Pérez Lacarta, Ana M.a, «Alteridad e identidad en la obra de Robert Margerit», $L$ Autre et soimême. La identidad y la alteridad en el ámbito francés y francófono. Editores: María Pilar Suárez, Margarita Alfaro, André Bénit, Patricia Martínez, Carmen Mata \& Didier Tejedor. Madrid: Universidad Autónoma de Madrid, 2004, pp. 655-665.

Perez LaCarta, Ana M. ${ }^{a}$, El universo imaginario de Robert Margerit: los espacios, Alicante: Biblioteca Virtual Miguel de Cervantes, 2004. 
Pujante González, Domingo, «Imágenes de la monstruosidad en la obra pánica de Fernando Arrabal y Roland Topar», L'Autre et soi-même. La identidad y la alteridad en el ámbito francés y francófono. Editores: María Pilar Suárez, Margarita Alfaro, André Bénit, Patricia Martínez, Carmen Mata \& Didier Tejedor. Madrid: Universidad Autónoma de Madrid, 2004, pp. 333-344.

Pujante González, Domingo, «Le sacré livre de Proutto de Roland Topor o cómo ser dios en una isla desierta», Isla abierta: estudios franceses en memoria de Alejandro Cioranescu [X Coloquio de la Asociación de Profesores de Filología Francesa de la Universidad Española. La Laguna, 2001], José M. Oliver Frade (coord.). La Laguna: Universidad de La Laguna, Servicio de Publicaciones, 2004, t. III, pp. 1133-1151.

Ramírez GómEZ, Carmen, "Catherine Millet y la nueva literatura erótica francesa». Philologia Hispalensis 16/2 (2004): 85-100.

Ramírez Gómez, Carmen, Dadá Prodigioso. Huelva: Cuademos Literarios la Placeta, Fundación el Monte, 2004, $180 \mathrm{pp}$.

Ramos GaY, Ignacio, «Du même à l'autre moyennant le monologue intérieur: L'Homme du Hasard de Yasmina Reza", L'Autre et soi-même. La identidad y la alteridad en el ámbito francés y francófono. Editores: María Pilar Suárez, Margarita Alfaro, André Bénit, Patricia Martínez, Carmen Mata \& Didier Tejedor. Madrid: Universidad Autónoma de Madrid, 2004, pp. 87-98.

Romero Pérez, M. "Clara, "Dualité de Roberte II ou l'archétype de la Femme Sauvage», Logosphère. Revista de Estudios Lingüisticos y Literarios. Identités 0 (2004): 149-166.

SAIZ Cerreda, M." Pilar, "Cartas de Antoine de Saint-Exupéry: hacia una recreación ontológica de su identidad", L'Autre et soi-même. La identidad y la alteridad en el ámbito francés y francófono. Editores: María Pilar Suárez. Margarita Alfaro, André Bénit, Patricia Martínez, Carmen Mata \& Didier Tejedor. Madrid: Universidad Autónoma de Madrid, 2004, pp. 667 676.

SÁNCHEZ HERNÁNDEZ. Ángeles, «Autobiografía y marginalidad en Annie Ernaux». L'Autre et soimême. La identidad y la alteridad en el ámbito francés y francófono. Editores: María Pilar Suárez, Margarita Alfaro, André Bénit, Patricia Martínez, Carmen Mata \& Didier Tejedor. Madrid: Universidad Autónoma de Madrid, 2004, pp. 677-686.

SÁNCHEZ HERnÁNDEZ, Ángeles, «Estudio de la relación madre-hija en la novela Une femme de Annie Ernaux», Isla abierta: estudios franceses en memoria de Alejandro Cioranescu [X Coloquio de la Asociación de Profesores de Filología Francesa de la Universidad Española. La Laguna, 2001], José M. Oliver Frade (coord.). La Laguna: Universidad de La Laguna, Servicio de Publicaciones, 2004, t. III, pp. 1237-1248.

SAnTA, M. Àngels, Pròleg, Els homes en general m'agraden molt de Véronique Ovaldé. Lleida: Pagès Editors, 2004, pp. 5-7.

SegarRa, Marta, «Hélène Cixous, écrivain indécidable», Migrations des identités et des textes entre l'Algérie et la France, dans les littératures des deux rives. Charles Bonn (ed.). París: L'Harmattan, 2004, pp. 185-192.

Segarra, Marta, «Hélène Cixous, la fiesta del significante», Hélène Cixous, Jacques Derrida y Marta Segarra (eds.), Lengua por venir/ Langue à venir. Seminario de Barcelona. Barcelona: Icaria, 2004, pp. 23-32

Segarra, Marta, Edición de Hélène Cixous, Deseo de escritura. Barcelona: Reverso, 2004, 182 pp. SERRANo MaÑes, Montserrat, "Quand écrire c'est se dire. De la vie à l'œuvre, la femme», Thélème. Revista Complutense de Estudios franceses 19 (2004): 171-182. [Marie Cardinal].

SiRvent Ramos, Ángeles, «La correspondence Valery Larbaud-André Gide, Léon-Paul Fargue. Adrienne Monnier (1916-1920)", Isla abierta: estudios franceses en memoria de Alejandro Cioranescu [X Coloquio de la Asociación de Profesores de Filología Francesa de la Universidad Española, La Laguna. 2001 ], José M. Oliver Frade (coord.). La Laguna: Universidad de La Laguna, Servicio de Publicaciones. 2004, t. III, pp. 1307-1320. 
SOLÀ SolÉ, Pere, «Les nouveaux chiens de garde o un léxico políticamente incorrecto», Isla abierta: estudios franceses en memoria de Alejandro Cioranescu [X Coloquio de la Asociación de Profesores de Filología Francesa de la Universidad Española, La Laguna, 2001], José M. Oliver Frade (coord.). La Laguna: Universidad de La Laguna, Servicio de Publicaciones, 2004, t. III, pp. 1321-1329.

SOlÉ CASTElls, Cristina, «La función del dinero en la obra novelística de Boris Vian», Isla abierta: estudios franceses en memoria de Alejandro Cioranescu [X Coloquio de la Asociación de Profesores de Filología Francesa de la Universidad Española, La Laguna, 2001], José M. Oliver Frade (coord.). La Laguna: Universidad de La Laguna, Servicio de Publicaciones, 2004, t. III, pp. 1331-1341.

SUÁREZ, M. ${ }^{2}$ Pilar, «La acción de la locura: la sottie en Chaillot», Renaissance \& Classicisme. Homenatge a Caridad Martínez. Edición de Francisco Lafarga \& Marta Segarra. Barcelona: PPU, pp. 283-299.

TERrón BARBOSA, Lourdes, «Encre noire: Voyage au bout de la nuit» Intertextes (Revue du Laboratoire de Littérature Française de l'Université de Théssalonique) 6 (2004): 134-147.

TOMAS, Ilda, "Gauguin, Segalen et la magie des îles», Isla abierta: estudios franceses en memoria de Alejandro Cioranescu [X Coloquio de la Asociación de Profesores de Filología Francesa de la Universidad Española, La Laguna, 2001], José M. Oliver Frade (coord.). La Laguna: Universidad de La Laguna, Servicio de Publicaciones, 2004, t. III, pp. 1371-1381.

Tomas, Ilda, «La Difficulté d' être avec soi-même et avec l'autre», L'Autre et soi-même. La identidad y la alteridad en el ámbito francés y francófono. Editores: María Pilar Suárez, Margarita Alfaro, André Bénit, Patricia Martínez, Carmen Mata \& Didier Tejedor. Madrid: Universidad Autónoma de Madrid, 2004, pp. 687-695. [Jean Cocteau].

VERDEGAL, Joan, «Un siglo de senectud y renovación en el jurado fémina», Isla abierta: estudios franceses en memoria de Alejandro Cioranescu [X Coloquio de la Asociación de Profesores de Filología Francesa de la Universidad Española, La Laguna, 2001], José M. Oliver Frade (coord.). La Laguna: Universidad de La Laguna, Servicio de Publicaciones, 2004, t. III, pp. 1459-1477.

\section{VARIOS SIGLOS}

Bideaux, Michel, «Or potable et pot au lait: destins d'un apologue médiéval de Des Périers à La Fontaine», Renaissance \& Classicisme. Homenatge a Caridad Martínez. Edición de Francisco Lafarga \& Marta Segarra. Barcelona: PPU, pp. 191-199.

Bollève Guerlet, Annick, «Expérience de soi et conscience de l'autre, l'écriture didactique chez Christine de Pizan et Gabrielle Suchon", L'Autre et soi-même. La identidad y la alteridad en el ámbito francés y francófono. Editores: María Pilar Suárez, Margarita Alfaro, André Bénit, Patricia Martínez, Carmen Mata \& Didier Tejedor. Madrid: Universidad Autónoma de Madrid, 2004, pp. 699-711.

CAmARERo, Jesús, Metaliteratura. Barcelona: Anthropos, 2004, 240 págs. [Mallarmé, Perec, Queneau, Robbe-Grillet, etc.].

Carmona Fernández, Femando, «Pervivencia literaria del mito demoníaco: los hijos del diablo», Europa y sus mitos, F. Carmona \& J. M. García Cano (eds.). Murcia: Universidad de Murcia, Servicio de Publicaciones, 2004, pp. 31-53.

Ramos Gomez, M. ${ }^{a}$ Teresa, De Silfos y Humanos. El Conde de Gabalís de Montfaucon de Villars y El Silfo de Claude Crébillon. Estudio, traducción y notas de M. ${ }^{\mathrm{a}}$ Teresa Ramos. Prólogo de Francisco Javier Hernández. Valladolid: Universidad de Valladolid, Disbabelia, colección de traducciones ignotas, $9,2004,156 \mathrm{pp}$. 
Yllera, Alicia, Velázquez, José Ignacio, BoiXareu, Mercedes y VÁzquez, Lydia, Literatura francesa. Segunda edición, corregida y aumentada. Madrid: Universidad Nacional de Educación a Distancia, 2004, 285 pp.

\section{LITERATURA DE EXPRESIÓN FRANCESA. LITERATURA EN LENGUA FRANCESA FUERA DE FRANCIA}

Agnant, Marie-Célie, «Écrire dans la langue reçue», L'Autre et soi-même. La identidad y la alteridad en el ámbito francés y francófono. Editores: María Pilar Suárez, Margarita Alfaro, André Bénit, Patricia Martínez, Carmen Mata \& Didier Tejedor. Madrid: Universidad Autónoma de Madrid, 2004, pp. 135-140.

ÁlvAREZ DE LA ROSA, Antonio, «De père français, de Michel del Castillo. Los restos del naufragio», Isla abierta: estudios franceses en memoria de Alejandro Cioranescu [X Coloquio de la Asociación de Profesores de Filología Francesa de la Universidad Española, La Laguna, 2001], José M. Oliver Frade (coord.). La Laguna: Universidad de La Laguna, Servicio de Publicaciones, 2004, t. I, pp. 63-70.

BaENa Galle, Violeta M.", «El mestizaje como única opción de supervivencia: el caso de Driss Chraïbi», L'Autre et soi-même. La identidad y la alteridad en el ámbito francés y francófono. Editores: María Pilar Suárez, Margarita Alfaro, André Bénit, Patricia Martínez, Carmen Mata \& Didier Tejedor. Madrid: Universidad Autónoma de Madrid, 2004, pp. 141-150.

BlÉRALD-NDAGaNo, Monique, «Maryse Condé: religion et discours social», Isla abierta: estudios franceses en memoria de Alejandro Cioranescu [X Coloquio de la Asociación de Profesores de Filología Francesa de la Universidad Española, La Laguna, 2001], José M. Oliver Frade (coord.). La Laguna: Universidad de La Laguna, Servicio de Publicaciones, 2004, t. I, pp. 213 225.

BLESER POTELle, Nathalie, «René Henoumont et la littérature française de Belgique: faux et usage de faux ou délit "d'inhibé", Histoire d' une identité», Logosphère. Revista de Estudios Lingüísticos y Literarios. Identités 0 (2004): 57-73.

CAmero Pérez, Carmen, «La nouvelle francophone en Belgique et en Suisse», La nouvelle francophone en Belgique et en Suisse. Université Jean Moulin-Lyon 3, C.E.D.I.C., 2004, pp. 103-112.

CARRIEDo López, Lourdes, «La metáfora mestiza en la Obra poética de L. S. Senghor», La literatura en la literatura. Actas del XIV simposio de la Sociedad Española de Literatura General y Comparada. Edición de Magdalena León Gómez. Alcalá de Henares: Centro de Estudios Cervantinos, 2004, pp. 175-183.

Cruz Rodriguez, José Manuel, «Analyse du discours et identité: étude de deux discours littéraires sur la plantation sucrière à propos de l'environnement et de l'être humain», Isla abierta: estudios franceses en memoria de Alejandro Cioranescu [X Coloquio de la Asociación de Profesores de Filología Francesa de la Universidad Española, La Laguna, 2001], José M. Oliver Frade (coord.). La Laguna: Universidad de La Laguna, Servicio de Publicaciones, 2004, t. I, pp. 391-410.

CUASANTE FERnÁNDEZ, Elena, «La literatura africana escrita por mujeres: de la novela testimonial a la novela comprometida", Isla abierta: estudios franceses en memoria de Alejandro Cioranescu [X Coloquio de la Asociación de Profesores de Filología Francesa de la Universidad Española, La Laguna, 2001], José M. Oliver Frade (coord.). La Laguna: Universidad de La Laguna, Servicio de Publicaciones, 2004, t. I, pp. 411-427.

DUCHÊNE, Nadia, «Construction identitaire et altérité dans Le Gone du Chaâba d'Azouz Begag», L'Autre et soi-même. La identidad y la alteridad en el ámbito francés y francófono. Editores: 
María Pilar Suárez, Margarita Alfaro, André Bénit, Patricia Martínez, Carmen Mata \& Didier Tejedor. Madrid: Universidad Autónoma de Madrid, 2004, pp. 151-160.

Fonkoua, Romuald, «Altérité et différence. Littérature et anthropologie», L'Autre et soi-même. La identidad y la alteridad en el ámbito francés y francófono. Editores: María Pilar Suárez, Margarita Alfaro, André Bénit, Patricia Martínez, Carmen Mata \& Didier Tejedor. Madrid: Universidad Autónoma de Madrid, 2004, pp. 405-416.

García CaSADo, Margarita, «Shérazade ou les parcours de je/ux de miroirs», L'Autre et soimême. La identidad y la alteridad en el ámbito francés y francófono. Editores: María Pilar Suárez, Margarita Alfaro, André Bénit, Patricia Martínez, Carmen Mata \& Didier Tejedor. Madrid: Universidad Autónoma de Madrid, 2004, pp. 161-170.

GarCía CELA, Carmen, «La tentation de l'autre corps: Orlanda de Jacqueline Harpmann», L'Autre et soi-même. La identidad y la alteridad en el ámbito francés y francófono. Editores: María Pilar Suárez, Margarita Alfaro, André Bénit, Patricia Martínez, Carmen Mata \& Didier Tejedor. Madrid: Universidad Autónoma de Madrid, 2004, pp. 75-85.

GASTÓN ELDUAYEN, Luis, «L'histoire, le mythe et l'identité dibienne. 1. Images telluriques, parole d'exil», Logosphère. Revista de Estudios Lingüísticos y Literarios. Identités 0 (2004): 75-98 [Mohammed Dib].

GonZÁlez DOPAZO, Olaya, «La construcción de una identidad excéntrica en la obra de Gabrielle Roy", L'Autre et soi-même. La identidad y la alteridad en el ámbito francés y francófono. Editores: María Pilar Suárez, Margarita Alfaro, André Bénit, Patricia Martínez, Carmen Mata \& Didier Tejedor. Madrid: Universidad Autónoma de Madrid, 2004, pp. 221-229.

GonZÁleZ MENÉNDEZ, Lidia, "Les "terres nouvelles" dans les reportages de Gabrielle Roy», Isla abierta: estudios franceses en memoria de Alejandro Cioranescu [X Coloquio de la Asociación de Profesores de Filología Francesa de la Universidad Española, La Laguna, 2001], José M. Oliver Frade (coord.). La Laguna: Universidad de La Laguna, Servicio de Publicaciones, 2004 , t. II, pp. 599-621.

Ibeas Vuelta, Nieves, «Michel del Castillo: la experiencia de "biografiar" la novela", L'Autre et soi-même. La identidad y la alteridad en el ámbito francés y francófono. Editores: María Pilar Suárez, Margarita Alfaro, André Bénit, Patricia Martínez, Carmen Mata \& Didier Tejedor. Madrid: Universidad Autónoma de Madrid, 2004, pp. 273-284.

LAVAL, Sophie, «Le nomadisme identitaire dans N'zid de Malika Mokeddem», Logosphère. Revista de Estudios Lingüísticos y Literarios. Identités 0 (2004): 115-131.

LEQUIN, Lucie, «La jointure du vivre et du livre», L'Autre et soi-même. La identidad y la alteridad en el ámbito francés y francófono. Editores: María Pilar Suárez, Margarita Alfaro, André Bénit, Patricia Martínez, Carmen Mata \& Didier Tejedor. Madrid: Universidad Autónoma de Madrid, 2004, pp. 171-180.

Mata BarReiro, Carmen, «Exil, mémoire, acculturation: la reconstruction de l'identité chez les écrivaines migrantes francophones», L'Autre et soi-même. La identidad y la alteridad en el ámbito francés y francófono. Editores: María Pilar Suárez, Margarita Alfaro, André Bénit, Patricia Martínez, Carmen Mata \& Didier Tejedor. Madrid: Universidad Autónoma de Madrid, 2004, pp. 181-192.

Molina RoMero, M. ${ }^{a}$ Carmen, «Agustin Gomez-Arcos: une écriture marquée par les parenthèses», Le français face aux défis actuels. J. Suso López \& R. López Carrillo (coord.). Granada: Universidad de Granada, 2004, vol. I.

Molina Romero, M. ${ }^{a}$ Carmen, «Littérature franco-espagnole?», Logosphère. Revista de Estudios Lingüisticos y Literarios. Identités 0 (2004): 133-147.

Molina Romero, M. ${ }^{a}$ Carmen, «Madres malas y literatura del exilio», Revista de Filología (Universidad de La Laguna) 22 (2004): 175-185.

MOlina Romero, M. ${ }^{a}$ del Carmen, «Jorge Semprun: de l'algarabie linguistique à l'algarabie narrative», Isla abierta: estudios franceses en memoria de Alejandro Cioranescu [X Coloquio 
de la Asociación de Profesores de Filología Francesa de la Universidad Española, La Laguna, 2001 ], José M. Oliver Frade (coord.). La Laguna: Universidad de La Laguna, Servicio de Publicaciones, 2004, t. II, pp. 879-893.

MONTES NOGALES, Vicente E., «La función de los personajes femeninos en L'étrange destin de Wangrin y la epopeya oesteafricana", L'Autre et soi-même. La identidad y la alteridad en el ámbito francés y francófono. Editores: María Pilar Suárez, Margarita Alfaro, André Bénit, Patricia Martínez, Carmen Mata \& Didier Tejedor. Madrid: Universidad Autónoma de Madrid, 2004, pp. 101-112.

PAGÁN LÓPEZ, Antonia, «Assia Djebar ou l'écriture-parole», Francofonía. Littérature et société dans la littérature francophone du Maghreb (Universidad de Cádiz) 12 (2003): 119-133.

PÉREZ de Dios, Sylvie, «Andrée Chedid: la escritura intercultural múltiple», La literatura en la literatura. Actas del XIV simposio de la Sociedad Española de Literatura General y Comparada. Edición de Magdalena León Gómez. Alcalá de Henares: Centro de Estudios Cervantinos, 2004, pp. 305-312.

POPA-Liseanu, Doina, «Destino Paris: cosmopolitas rumanos en busca de la fama universal», Isla abierta: estudios franceses en memoria de Alejandro Cioranescu [X Coloquio de la Asociación de Profesores de Filología Francesa de la Universidad Española, La Laguna, 2001], José M. Oliver Frade (coord.). La Laguna: Universidad de La Laguna, Servicio de Publicaciones, 2004, t. III, pp. 1079-1093.

POPA-LISEANU, Doina, «Pleurer l'exil?», Exils imaginaires \& exils réels dans le domaine francophone. El Jadida: Université Chouaỉb Doukkali, Faculté des lettres, 2004, pp. 307-316.

PORRAS MEDRANO, Adelaida, «Funciones de la autorrepresentación en L'Enfant noir de Camara Laye", L'Autre et soi-même. La identidad y la alteridad en el ámbito francés y francófono. Editores: María Pilar Suárez, Margarita Alfaro, André Bénit, Patricia Martínez, Carmen Mata \& Didier Tejedor. Madrid: Universidad Autónoma de Madrid, 2004, pp. 113-122.

RENOUPREZ, Martine, "Gestation et accouchement chez quelques écrivaines belges francophones à partir des années 70», Isla abierta: estudios franceses en memoria de Alejandro Cioranescu [X Coloquio de la Asociación de Profesores de Filologia Francesa de la Universidad Española, La Laguna, 2001], José M. Oliver Frade (coord.). La Laguna: Universidad de La Laguna, Servicio de Publicaciones, 2004, t. III, pp. 1153-1169.

Ruiz Álvarez, Rafael, «Effondrer l'identité. Jeu de rôles dans le théâtre de Abdellatif Laâbi», L'Autre et soi-même. La identidad y la alteridad en el ámbito francés y francófono. Editores: María Pilar Suárez, Margarita Alfaro, André Bénit, Patricia Martínez, Carmen Mata \& Didier Tejedor. Madrid: Universidad Autónoma de Madrid, 2004, pp. 123-132.

SANTA, M. ${ }^{a}$ Àngels, Pròleg y notas, L'angoixa dels rebels de Malika Mokeddem. Lleida: Pagès Editors, 2004, pp. 5-8.

SegarRA, Marta, «El "continent obscur": poetes francòfones africanes», Escriptores $i$ cultures. Marta Segarra y Àngels Carabí (eds.). Barcelona: Pòrtic, 2004, pp. 41-60.

SEgARRA, Marta, «Les romancières francophones du Maghreb dans une perspective méditerranéenne", Les femmes entre violences et stratégies de liberté. Maghreb et Europe du sud. Ch. Veauvy, M. Rollinde \& M. Azzoug (eds.). Saint-Denis: Éditions Bouchène, 2004, pp. 177-186.

SERRANO MAÑES, Montserrat, «Jeux de mémoire, quête identitaire: Garçon manqué», Logosphère. Revista de Estudios Lingüísticos y Literarios. Identités 0 (2004): 167-185 [Nina Bouraoui].

SERrano MAÑEs, Montserrat, "Nina Bouraoui, ou le regard libérateur d'une écriture migrante», Francofonía 12 (2003): 181-193. [La voyeuse interdite de Nina Bouraoui].

TERrón Barbosa, Lourdes, «El azar aprisionado. Mélusine/ Nébuleuse y la vuelta de las hadas: de La région du cour à Le traité des fées con Femand Dumont», Isla abierta: estudios franceses en memoria de Alejandro Cioranescu [X Coloquio de la Asociación de Profesores de Filología Francesa de la Universidad Española, La Laguna, 2001], José M. Oliver Frade (coord.). La Laguna: Universidad de La Laguna, Servicio de Publicaciones, 2004, t. III, pp. 1359-1370. 
TERRÓN BARBOSA, Lourdes, «Le règne végétal, source et champ analogique dans la poésie d'Achille Chavée», Francofonía 13 (2004): 160-190.

\section{LITERATURA DE VIAJES}

CIORANESCU, Alejandro: Crónicas francesas de la conquista de Canarias. Le Canarien. Nueva edición al cuidado de Antonio Álvarez de la Rosa y José M. Oliver Frade. Santa Cruz de Tenerife: Ediciones Idea, 2004. (Colección Rescate).

GONZÁLEZ DE URIARTE, Cristina, «La mujer canaria en la literatura de viajes francesa», Isla abierta: estudios franceses en memoria de Alejandro Cioranescu [X Coloquio de la Asociación de Profesores de Filología Francesa de la Universidad Española, La Laguna, 2001], José M. Oliver Frade (coord.). La Laguna: Universidad de La Laguna, Servicio de Publicaciones, 2004, t. II, pp. 567-581.

Pico Graña, Berta, "Alejandro Cioranescu, editor de Le Canarien», Isla abierta: estudios franceses en memoria de Alejandro Cioranescu [X Coloquio de la Asociación de Profesores de Filología Francesa de la Universidad Española, La Laguna, 2001], José M. Oliver Frade (coord.). La Laguna: Universidad de La Laguna, Servicio de Publicaciones, 2004, t. III, pp. 1055-1068.

CURELL, Clara, «Algunas consideraciones en tomo a las Impressions et observations dans un voyage a Tenerife: de Jean Mascart», Isla abierta: estudios franceses en memoria de Alejandro Cioranescu [X Coloquio de la Asociación de Profesores de Filología Francesa de la Universidad Española, La Laguna, 2001], José M. Oliver Frade (coord.). La Laguna: Universidad de La Laguna, Servicio de Publicaciones, 2004, t. I, pp. 429-441.

\section{LITERATURA COMPARADA. RECEPCIÓN LITERARIA. LITERATURA Y CINE}

BENOrT, Claude, «El petrarquismo en Alain Chartier y Bernat Hug de Rocaberti», Palabras y recuerdos. Homenaje a Rosa María Calvet Lora. Édition de M. ${ }^{a}$ Rosario Ozaeta, Doina Popa-Liseanu \& Alicia Yllera. Madrid: UNED, Departamento de Filología Francesa, 2004, pp. 21-29.

CARMONA FERNÁNDEZ, Fernando, «El caballero y sus demonios: combates infernales en los libros de caballería", Cuadernos del CEMYR 11 (diciembre 2003): 9-33.

CARMONa Fernández, Fernando, «Tristán y la narrativa trágica en las cantigas de amor», $O$ «Cancioneiro da Ajuda», cen anos despois. Actas do Congreso realizado por la Dirección Xeral de Promoción Cultural en Santiago de Compostela e na Illa de San Simón os días 25-28 de maio de 2004. Xunta de Galicia: Consellería de Cultura, Comunicación Social e Turismo, 2004, pp. 243-260.

Casas NaDAl, Montserrat, «Los Discursos de Francesco Panigarola (1548-1594) en Notre-Dame de París. Su traducción y recepción en España», Renaissance \& Classicisme. Homenatge a Caridad Martínez. Edición de Francisco Lafarga \& Marta Segarra. Barcelona: PPU, pp. 263-276.

Escobar Chimeno, Paola, «El Ser y la Nada. La destrucción como creación. Los ejemplos de Stéphane Mallarmé y La Voluntad de Azorín", La literatura en la literatura. Actas del XIV simposio de la Sociedad Española de Literatura General y Comparada. Edición de Magdalena León Gómez. Alcalá de Henares: Centro de Estudios Cervantinos, 2004, pp. 449-456.

Fernández Garrido, M.* Regla, «El suicidio de Antígona en las obras de Sófocles y Jean Anouilh», La literatura en la literatura. Actas del XIV simposio de la Sociedad Española de Literatura General y Comparada. Edición de Magdalena León Gómez. Alcalá de Henares: Centro de Estudios Cervantinos, 2004, pp. 515-523. 
GÉRARD Lojacono, Florence, «Une île, des îles. Le voyage sans fin au pays qui te resemble», Isla abierta: estudios franceses en memoria de Alejandro Cioranescu [X Coloquio de la Asociación de Profesores de Filología Francesa de la Universidad Española, La Laguna, 2001], José M. Oliver Frade (coord.). La Laguna: Universidad de La Laguna, Servicio de Publicaciones, 2004, t. II, pp. 555-566.

GINE, Marta y DOMÍNGUEZ, Yolanda, «Traducciones de la literatura francesa ordenadas por autores», Premsa hispànica i literatura francesa al segle XIX: petites i grans ciutats/Prensa hispánica y literatura francesa en el siglo XIX: pequeñas y grandes ciudades. Marta Giné \& Yolanda Domínguez (eds.). Lleida: Edicions de la Universitat de Lleida, 2004, pp. 321-338.

GINE, Marta y RIBES, Àngels, « ¿Cuánto cuento! A modo de epílogo», Premsa hispànica i literatura francesa al segle XIX: petites $i$ grans ciutats/Prensa hispánica y literatura francesa en el siglo XIX: pequeñas y grandes ciudades. Marta Giné \& Yolanda Domínguez (eds.). Lleida: Edicions de la Universitat de Lleida, 2004, pp. 307-320.

GINE, Marta, «Diaris lleidatans (s. XIX) amb objectius programàtics literaris», Premsa hispànica $i$ literatura francesa al segle XIX: petites $i$ grans ciutats/Prensa hispánica y literatura francesa en el siglo XIX: pequeñas y grandes ciudades. Marta Giné \& Yolanda Domínguez (eds.). Lleida: Edicions de la Universitat de Lleida, 2004, pp. 161-168.

GINÉ, Marta, «Premsa hispànica i literatura francesa (s. XIX). Estudi d'una relació controvertida», Premsa hispànica i literatura francesa al segle XIX: petites $i$ grans ciutats/ Prensa hispánica y literatura francesa en el siglo XIX: pequeñas y grandes ciudades. Marta Giné \& Yolanda Domínguez (eds.). Lleida: Edicions de la Universitat de Lleida, 2004, pp. 13-20.

GONZÁLEZ SANTANA, Rosa Delia, «La mujer trabajadora en el siglo XIX: narrativa y realidad», Isla abierta: estudios franceses en memoria de Alejandro Cioranescu [X Coloquio de la Asociación de Profesores de Filología Francesa de la Universidad Española, La Laguna, 2001], José M. Oliver Frade (coord.). La Laguna: Universidad de La Laguna, Servicio de Publicaciones, 2004 , t. II, pp. 643-654.

HERnÁNDEZ, Esther y SIERRA, Lina, «La ciudad de París, espacio geográfico y simbólico en André Breton y Jean Rhys», La literatura en la literatura. Actas del XIV simposio de la Sociedad Española de Literatura General y Comparada. Edición de Magdalena León Gómez. Alcalá de Henares: Centro de Estudios Cervantinos, 2004, pp. 541-549.

LAFARGA, Francisco, «Los grands auteurs clásicos franceses y su recepción en España. Encuentros y desecuentros», Renaissance \& Classicisme. Homenatge a Caridad Martínez. Francisco Lafarga \& Marta Segarra (eds.). Barcelona: PPU, 2004, pp. 315-331.

LAFARGA, Francisco, «Nombres propios de la literatura francesa en El Vapor (1833-1836)», Premsa hispànica i literatura francesa al segle XIX: petites i grans ciutats/Prensa hispánica y literatura francesa en el siglo XIX: pequeñas y grandes ciudades. Marta Giné \& Yolanda Domínguez (eds.). Lleida: Edicions de la Universitat de Lleida, 2004, pp. 47-64.

Luna Alonso, Ana, «La recepción de la literatura francesa en el sistema literario gallego», Anales de Filología Francesa. La traducción 12 (2004): 233-247.

MARTINEZ PÉREZ, Antonia, «El mito artúrico en la literatura caballeresca catalana: La Faula y Tirant lo blanc", Europa y sus Mitos, F. Carmona \& J. M. García Cano (eds.). Murcia: Universidad de Murcia, Servicio de Publicaciones, 2004, pp. 143-158.

NDAGANO, Biringanine, «Diderot/Coelho: du grand rouleau à la légende personnelle», Isla abierta: estudios franceses en memoria de Alejandro Cioranescu [X Coloquio de la Asociación de Profesores de Filología Francesa de la Universidad Española, La Laguna, 2001], José M. Oliver Frade (coord.). La Laguna: Universidad de La Laguna, Servicio de Publicaciones, 2004, t. II, pp. 911-922.

NiUBó, Iolanda y BURRIAL, Xavier, «A. Théuriet, un autor costumbrista de moda: Textos y traducción en la prensa leridana», Premsa hispànica i literatura francesa al segle XIX: petites $i$ grans 
ciutats/ Prensa hispánica y literatura francesa en el siglo XIX: pequeñas y grandes ciudades. Marta Giné \& Yolanda Domínguez (eds.). Lleida: Edicions de la Universitat de Lleida, 2004, pp. 279-296.

Pacheco Caballero, M." Jesús, «Musique et littérature: Pelléas et Mélisande», Isla abierta: estudios franceses en memoria de Alejandro Cioranescu [X Coloquio de la Asociación de Profesores de Filología Francesa de la Universidad Española, La Laguna, 2001], José M. Oliver Frade (coord.). La Laguna: Universidad de La Laguna, Servicio de Publicaciones, 2004, t. II, pp. 949-959.

PaGeauX, Daniel-Henri, «ldentité, Altérité, Francophonie. Perspectives Comparatistes ", L'Autre et soi-même. La identidad y la alteridad en el ámbito francés y francófono. Editores: María Pilar Suárez, Margarita Alfaro, André Bénit, Patricia Martínez, Carmen Mata \& Didier Tejedor. Madrid: Universidad Autónoma de Madrid, 2004, pp. 25-48.

Palacios Bernal, Concepción, «Crítica literaria y narradores franceses en La España Moderna», Premsa hispànica i literatura francesa al segle XIX: petites $i$ grans ciutats/Prensa hispánica y literatura francesa en el siglo XIX: pequeñas y grandes ciudades. Marta Giné \& Yolanda Domínguez (eds.). Lleida: Edicions de la Universitat de Lleida, 2004, pp. 109-125.

Palacios Bernal, Concepción, «Narrativa francesa en La llustración artística», Palabras y recuerdos. Homenaje a Rosa María Calvet Lora. Édition de M. ${ }^{a}$ Rosario Ozaeta, Doina Popa-Liseanu \& Alicia Yllera. Madrid: UNED, Departamento de Filología Francesa, 2004, pp. 183186.

Pérez Varela, Carlos, «Richard de Fournival e Fernan Rodriguez de Calheiros: orguel ou sobervia», Boletín Galego de Literatura (Universidade de Santiago de Compostela) 29 ( $1^{\circ}$ semestre 2003): 45-59.

PiQuer Desvaux, Alicia, «Pierre Reverdy et Juan Gris: dialogues», Confluencias poéticas. Estética, recepción y traducción de la poesía francesa contemporánea. Marie-France Borot \& Alicia Piquer Desvaux (eds.). Barcelona: PPU, 2004, pp. 61-73.

RaVENTÓS BaRANGE, Anna, "Rupture et continuité dans l'après-Lumières: avatars du héros bâtard de part et d'autre du Rhin », Estudios Filologicos Alemanes 6 (2004): 301-325.

Romera CASTtLlo, José, «Algo más sobre la presencia del teatro de Alejandro Dumas (hijo) en algunos escenarios españoles del siglo XIX», Palabras y recuerdos. Homenaje a Rosa María Calvet Lora. Édition de M. ${ }^{a}$ Rosario Ozaeta, Doina Popa-Liseanu \& Alicia Yllera. Madrid: UNED, Departamento de Filologia Francesa, 2004, pp. 193-203.

Santos Puerto, José, «La penetración de Rousseau en España: el caso de El Pensador de Clavijo y Fajardo", Isla abierta: estudios franceses en memoria de Alejandro Cioranescu [X Coloquio de la Asociación de Profesores de Filología Francesa de la Universidad Española, La Laguna, 2001], José M. Oliver Frade (coord.). La Laguna: Universidad de La Laguna, Servicio de Publicaciones, 2004, t. III, pp. 1249-1262.

SANZ, Teófilo, «Balzac y la música», Isla abierta: estudios franceses en memoria de Alejandro Cioranescu [X Coloquio de la Asociación de Profesores de Filología Francesa de la Universidad Española, La Laguna, 2001], José M. Oliver Frade (coord.). La Laguna: Universidad de La Laguna, Servicio de Publicaciones, 2004, t. III, pp. 1263-1272.

Zambrano Carbello, Pablo, «Suicidio y modernidad: los paradigmas de Flaubert y Dostoievski», La literatura en la literatura. Actas del XIV simposio de la Sociedad Española de Literatura General y Comparada. Edición de Magdalena León Gómez. Alcalá de Henares: Centro de Estudios Cervantinos, 2004, pp. 439-447. 
12. Historia de las ideas literarias. Crítica literaria. GÉnEros. ESTUDIOS DE TEMAS

Camarero Arribas, Jesús, «Teoría literaria y práctica comparatista», Isla abierta: estudios franceses en memoria de Alejandro Cioranescu [X Coloquio de la Asociación de Profesores de Filología Francesa de la Universidad Española, La Laguna, 2001], José M. Oliver Frade (coord.). La Laguna: Universidad de La Laguna, Servicio de Publicaciones, 2004, t. I, pp. 291-305.

Fernández Cardo, José M. ${ }^{a}$, «Pero esto es otra historia», Palabras y recuerdos. Homenaje a Rosa María Calvet Lora. Édition de M. ${ }^{\mathrm{a}}$ Rosario Ozaeta, Doina Popa-Liseanu \& Alicia Yllera. Madrid: UNED, Departamento de Filología Francesa, 2004, pp. 69-74.

Molina Romero, M. ${ }^{a}$ Carmen, «Double langue et création littéraire», Imaginaire et inconscient. L'homme et ses doubles, L'Esprit du Temps 14 (2004): 189-203.

Palma Borrego, M. José, «La Ley del género y su relación con el "sujeto" y la subjetividad femenina en el "relato de cura" femenino", L'Autre et soi-même. La identidad y la alteridad en el ámbito francés y francófono. Editores: María Pilar Suárez, Margarita Alfaro, André Bénit, Patricia Martínez, Carmen Mata \& Didier Tejedor. Madrid: Universidad Autónoma de Madrid, 2004, pp. 645-653.

PARdo Jiménez, Pedro, «La cuestión del juicio literario: notas para un balance», Isla abierta: estudios franceses en memoria de Alejandro Cioranescu [X Coloquio de la Asociación de Profesores de Filología Francesa de la Universidad Española, La Laguna, 2001], José M. Oliver Frade (coord.). La Laguna: Universidad de La Laguna, Servicio de Publicaciones, 2004, t. II, pp. 977-991.

PÉREz VARela, Carlos, Tradución e presentación de $O$ campo literario de Pierre Bourdieu. Santiago de Compostela: Edicións Laiovento, 2004, 132 pp.

RAMOS GAY, Ignacio, «La crítica como arte en Wilde y Baudelaire», La literatura en la literatura. Actas del XIV simposio de la Sociedad Española de Literatura General y Comparada. Edición de Magdalena León Gómez. Alcalá de Henares: Centro de Estudios Cervantinos, 2004, pp. 369-378.

\section{ESTUDIOS SOBRE LA TRADUCCIÓN LITERARIA}

ARREGUI BARRAGÁN, Natalia, «Traducir una obra literaria: un arte y un reto», Traducción, lengua y cultura: VIII Jornadas hispano-rusas de traducción e interpretación: Granada, 8-11 de abril de 2003. J. A. Sabio et al. (eds.). Granada: Jizo Ediciones, 2004, pp. 45-50.

Camero Pérez, Carmen y Bermúdez Medina, Dolores, «El color de Huysmans: un reto para la traducción de À Rebours», Estudios de Lengua y Literatura Francesas 15 (2004): 151-166.

CAMERo Pérez, Carmen y Bermúdez Medina, Dolores, «El paisaje en la traducción española de $\grave{A}$ Rebours», Estudios de Lengua y Literatura Francesas 15 (2004): 129-149.

Camero Pérez, Carmen, Bermúdez Medina, Dolores, González Rodriguez, Pilar, Lecrivain Viel, Claudine, Mora Millán, M. ${ }^{a}$ Luisa, Romero Alfaro, M. ${ }^{a}$ Elena, Prácticas de lectura y traducción: las denominaciones de color en traducciones españolas y francesas de textos literarios. Estudios de Lengua y Literatura Francesas 15 (2004): 7-21.

CAMPOS, Nicolás, «Un soneto: cuatro lecturas», Isla abierta: estudios franceses en memoria de Alejandro Cioranescu [X Coloquio de la Asociación de Profesores de Filología Francesa de la Universidad Española, La Laguna, 2001], José M. Oliver Frade (coord.). La Laguna: Universidad de La Laguna, Servicio de Publicaciones, 2004, t. I, pp. 307-320. [Cuatro traducciones francesas de un soneto de Shakespeare]. 
CLOUET, Richard y SÁNCHEZ HERNÁNDEZ, Ángeles, «Remarques sur la traduction littéraire: un exemple pratique autour des traductions espagnole et anglaise de La Place de A. Emaux», Anales de Filología Francesa. La traducción 12 (2004): 67-79.

DURNERIN, James, «Las Ruinas de Palmira de Volney, en la traducción del abate Marchena», Anales de Filología Francesa. La traducción 12 (2004): 95-105.

GARCia PRADAS, Ramón, «Anotaciones en torno a la traducción de la literatura francesa medieval: del texto al traductor», Anales de Filología Francesa. La traducción 12 (2004): 135-149.

Grijalba Castanos, Covadonga, «Estudio diacrónico de una traducción ¿un envejecimiento saludable?», Anales de Filología Francesa. La traducción 12 (2004): 177-199 [Candide de Voltaire].

IÑARREA LAS HeRAS, Ignacio, «Narrativa jacobea? Les pélerins de Saint-Jacques, nouvelle espagnole», Isla abierta: estudios franceses en memoria de Alejandro Cioranescu [X Coloquio de la Asociación de Profesores de Filología Francesa de la Universidad Española, La Laguna, 2001], José M. Oliver Frade (coord.). La Laguna: Universidad de La Laguna, Servicio de Publicaciones, 2004, t. II, pp. 675-690. [Traducción de Las dos doncellas de Cervantes].

Joyful Babel: Translating Hélène Cixous. Myriam Diocaretz y Marta Segarra (eds.). Amsterdam: Rodopi, 2004, 224 págs.

LAFARGA, Francisco, « ¿Traducir el canon? Cara y cruz de la traducción de los grands auteurs franceses del siglo XIX en España», Anales de Filología Francesa. La traducción 12 (2004): 215 232.

LAFARGA, Francisco, «El siglo XVIII, de la Ilustración al Romanticismo», Historia de la traducción en España. Francisco Lafarga \& Luis Pegenaute (eds.). Salamanca: Ambos Mundos, 2004, pp. 209-318 («Biblioteca de traducción», 9).

LAFARGa, Francisco, «Familia y burguesía en el teatro: el caso de las traducciones de Diderot», Historia social y literatura. Familia y burguesía en España (siglos XVIII-XIX). Roberto Fernández \& Jacques Soubeyroux (eds.). Lleida: Editorial Milenio, 2003, pp. 81-91.

LAFARGA, Francisco, «José Marchena y la traducción», Quaderns de Filologia. Estudis lingüístics. Número monográfico: Historia de la traducción. Brigitte Lépinette \& Antonio Melero (eds.) 8 (2003): 171-179.

LAFARGA, Francisco, «Referentes franceses en el discurso sobre la traducción en la España del siglo XVIII», Isla abierta: estudios franceses en memoria de Alejandro Cioranescu [X Coloquio de la Asociación de Profesores de Filología Francesa de la Universidad Española, La Laguna, 2001], José M. Oliver Frade (coord.). La Laguna: Universidad de La Laguna, Servicio de Publicaciones, 2004, t. II, pp. 721-738.

LAFARGA, Francisco, «Traducción, adaptación, trasvase de género: la Manón Lescaut de J. Benavente», Ética y política de la traducción en la época contemporánea. Assumpta Camps (ed.). Barcelona: PPU, 2004, pp. 295-302.

LAFARGA, Francisco, «Traducciones de G. Sand publicadas por Oliva (Barcelona, 1837-1838)», George Sand, 1804-2004. L'île et la dame de Nohant. Palma: Estudi Genera Lul lià, 2004, pp. 209-215 («Mallorca en el món»).

LAFARGA, Francisco, «Traduciendo al "otro” Montesquieu. La versión del Temple de Gnide por J. Roca i Cornet", Palabras y recuerdos. Homenaje a Rosa María Calvet Lora. Édition de M." Rosario Ozaeta, Doina Popa-Liseanu \& Alicia Yllera. Madrid: UNED, Departamento de Filología Francesa, 2004, pp. 119-122.

MALINGRET, Laurence, Stratégies de traduction: les lettres hispaniques en langue française. Arras: Artois Presses Université, Collection Traductologie, 2002.

MarTínez Cuadrado, Jerónimo, «Traducción al español de Les Antiquités de Rome de Joachim Du Bellay», Anales de Filología Francesa. La traducción 12 (2004): 249-264.

Molina Romero, M. a Carmen, «Puntuación y traducción en un texto bilingüe de Agustín Gómez Arcos», Anales de Filología Francesa. La traducción 12 (2004): 265-275. 
MorCILlo, Françoise, «Quand un poète traduit un autre poète. Manuel Álvarez Ortega y Miguel Veyrat», Anales de Filología Francesa. La traducción 12 (2004): 277-304.

Oliver, José M. y Curell, Clara, «Ejercicios de traducción poética: Sous le soleil de Max Elskamp», Anales de Filología Francesa. La traducción 12 (2004): 305-322.

Ozaeta Gálvez, M. ${ }^{a}$ Rosario, «Bernardo María de Calzada, traductor de La Fontaine», Anales de Filología Francesa. La traducción 12 (2004): 333-355.

OzAETA, M. ${ }^{a}$ Rosario, «En torno a la traducción poética: un modelo de la época ilustrada», Palabras y recuerdos. Homenaje a Rosa María Calvet Lora. Édition de M. ${ }^{a}$ Rosario Ozaeta, Doina Popa-Liseanu \& Alicia Yllera. Madrid: UNED, Departamento de Filología Francesa, 2004, pp. 177-182.

Piquer Desvaux, Alicia, «Poeta y traductor: de la traducción a la creación», Anales de Filología Francesa. La traducción 12 (2004): 357-369.

Ribelles Hellín, Norma, «Las notas a pie de página en las versiones al español de las novelas de Patrick Modiano: "la honte du traducteur"?», Anales de Filología Francesa. La traducción 12 (2004): 385-393.

Romero PÉrez, M.a Claire, «Histoire du soldat de Charles-Ferdinand Ramuz, sur une musique d'Igor Stravinsky, adaptée par Rafael Alberti: un prodige d'adaptation théâtrale», Le Français face aux défis actuels. Histoire, langue et culture. Granada: Universidad de Granada, 2004, vol. II, pp. 413-423.

SAURA SÁNCHEZ, Alfonso, «La colección de Heroidas traducidas por D.M.A. de C.», Isla abierta: estudios franceses en memoria de Alejandro Cioranescu [X Coloquio de la Asociación de Profesores de Filología Francesa de la Universidad Española, La Laguna, 2001], José M. Oliver Frade (coord.). La Laguna: Universidad de La Laguna, Servicio de Publicaciones, 2004, t. III, pp. 1273-1292.

SAURA SÁNCHEZ, Alfonso, «Le jeune Iriarte traducteur de Destouches», Anales de Filología Francesa. La traducción 12 (2004): 413-434.

SAura, Alfonso, «¿Actualización o recreación?: Bretón traductor de Destouches», Palabras y recuerdos. Homenaje a Rosa María Calvet Lora. Édition de M. ${ }^{a}$ Rosario Ozaeta, Doina PopaLiseanu \& Alicia Yllera. Madrid: UNED, Departamento de Filología Francesa, 2004, pp. 213-218.

Segarra, Marta, «Critical Introduction», Joyful Babel: Translating Hélène Cixous. Myriam Diocaretz y Marta Segarra (eds.). Amsterdam: Rodopi, 2004, pp. 7-22.

VERBEKE, Frederik, «Traduction et interculturalité: Émile Verhaeren au Pays Basque», L'Autre et soi-même. La identidad y la alteridad en el ámbito francés y francófono. Editores: María Pilar Suárez, Margarita Alfaro, André Bénit, Patricia Martínez, Carmen Mata \& Didier Tejedor. Madrid: Universidad Autónoma de Madrid, 2004, pp. 455-464.

Villacampa BuEno, Marta, «La traducción dramática como reescritura. Análisis de Art de Yasmina Reza y de su traducción española», L'Autre et soi-même. La identidad y la alteridad en el ámbito francés y francófono. Editores: María Pilar Suárez, Margarita Alfaro, André Bénit, Patricia Martínez, Carmen Mata \& Didier Tejedor. Madrid: Universidad Autónoma de Madrid, 2004, pp. 465-476.

YLLERA, Alicia, «Apuntes acerca de la traducción literaria: la traducción de Rabelais», Isla abierta: estudios franceses en memoria de Alejandro Cioranescu [X Coloquio de la Asociación de Profesores de Filología Francesa de la Universidad Española, La Laguna, 2001], José M. Oliver Frade (coord.). La Laguna: Universidad de La Laguna, Servicio de Publicaciones, 2004, t. III, pp. 1479-1495. 
14. Bibliografías. Estados de la CUESTión

Oliver Frade, José M., "Invitación al viaje: internet y literatura francesa», Isla abierta: estudios franceses en memoria de Alejandro Cioranescu [X Coloquio de la Asociación de Profesores de Filología Francesa de la Universidad Española, La Laguna, 2001], José M. Oliver Frade (coord.). La Laguna: Universidad de La Laguna, Servicio de Publicaciones, 2004, t. II, pp. 923947.

YLLERA, Alicia, «Publicaciones sobre literatura francesa en España (2002)», Epos 19 (2003): 347374. 